\title{
Lymph Node Metastasis Location and Postoperative Adjuvant Chemotherapy in Patients With pN1 Stage IIB Non-small Cell Lung Cancer
}

\author{
RYUICHI ITO, TAKUMA TSUKIOKA, NOBUHIRO IZUMI, HIROAKI KOMATSU, \\ HIDETOSHI INOUE, TAKUYA KIMURA, KAZUYA KISHIMOTO and NORITOSHI NISHIYAMA \\ Department of Thoracic Surgery, Osaka City University, Osaka, Japan
}

\begin{abstract}
Background/Aim: The benefit of adjuvant chemotherapy for patients with pN1 non-small cell lung cancer (NSCLC) according to the location of lymph node (LN) metastases remains unclear. In this study, we examined the location of LN metastasis and prognosis to identify the significance of adjuvant chemotherapy. Patients and Methods: Thirty-five patients with pathological Tla-2bN1MO NSCLC who underwent curative resection between 2010 and 2016 were enrolled in the study. We defined patients with LN metastasis extending in stations 10-12 as the hilar group $(n=22)$, and only in stations 13-14 as the intralobar group $(n=13)$. Results: There was a significant difference in the overall survival (OS) $(p=0.042)$ and disease-free survival (DFS) rates $(p=0.021)$ between the intralobar and hilar groups. In the intralobar group, there were no significant differences in the OS and DFS rates according to adjuvant chemotherapy. However, patients without adjuvant chemotherapy had a poorer OS $(p<0.001)$ and DFS rates $(p<0.001)$ in the hilar group. Conclusion: Prognosis significantly differed according to adjuvant chemotherapy in the hilar group.
\end{abstract}

Platinum-doublet therapy is recommended as adjuvant chemotherapy in patients with non-small cell lung cancer (NSCLC) and lymph node (LN) metastasis (1-4). However, platinum agents such as cisplatin have many toxic side-effects (5), so the burden of platinum-based chemotherapy on postoperative patients is considered to be large. In fact, the

This article is freely accessible online.

Correspondence to: Ryuichi Ito, MD, Department of Thoracic Surgery, Osaka City University, 1-4-3 Asahimachi, Abeno-ku, Osaka 545-8585, Japan. Tel: +81 666453841, Fax: +81 666466057, e-mail: 1988ryuichi@gmail.com

Key Words: Adjuvant chemotherapy, pN1, non-small cell lung cancer, metastatic location. benefit of platinum-based adjuvant chemotherapy has not been observed in patients with stage IA [hazard ratio $(\mathrm{HR})=1.40$; $95 \%$ confidence interval $(\mathrm{CI})=0.95-2.06]$ in the LACE trial (4). This might be due to the toxicity of cisplatin to the body, which outweighs the benefits of tumor suppression. In addition, IALT did not show any survival benefit in pathological $\mathrm{T} 1-2 \mathrm{~N} 1$ disease $(\mathrm{HR}=0.94 ; 95 \% \mathrm{CI}=0.80-1.11)$ (2). The indications for adjuvant chemotherapy use with cisplatin should be carefully evaluated.

Pathologic N1 LNs are classified into five stations corresponding to their anatomical locations: hilar LNs, interlobar LNs, lobar LNs, segmental LNs, and subsegmental LNs being termed stations 10, 11, 12, 13, and 14, respectively (6). In pN1 patients, $\mathrm{LN}$ metastasis may extend to the hilar or intralobar LNs. It is commonly reported that prognosis in $\mathrm{pN} 1$ patients varies depending on the location of metastatic LNs (7-10).

Therefore, the importance of adjuvant chemotherapy varies in patients with $\mathrm{pN} 1$ NSCLC according to the location of LN metastasis. However, there is no study comparing the prognostic benefit of adjuvant chemotherapy according to the location of LN metastasis. In this study, we investigated the location and prognosis of LN metastases in patients with pN1 stage IIB NSCLC and examined the suitability of adjuvant chemotherapy.

\section{Patients and Methods}

We retrospectively investigated the clinical courses of 566 patients who underwent curative resection (more than lobectomy and ND2a1) for NSCLC between January 2010 and December 2016. Before surgery, all patients provided informed consent for the use of their examination outcomes and clinical data in clinical studies. The local institutional ethics committee approved this study (approval no. 2020-247; approval date, January 7, 2021).

A total of 35 patients with pathological T1a-2bN1M0 (UICC-8) were enrolled in this study. We defined patients with $\mathrm{LN}$ metastasis extending in stations 10-11-12 as the hilar group, and patients with LN metastasis in stations 13-14 only as the intralobar group. We divided the 35 patients into two groups according to the location of 
Table I. Association of pectoralis muscle composition parameters with clinical variables (univariable model).

\begin{tabular}{|c|c|c|c|}
\hline & \multicolumn{2}{|c|}{ Location of lymph node metastasis } & \multirow[b]{2}{*}{$p$-Value } \\
\hline & $\begin{array}{l}\text { Hilar group } \\
\quad(\mathrm{n}=22)\end{array}$ & $\begin{array}{l}\text { Intralobar group } \\
\qquad(\mathrm{n}=13)\end{array}$ & \\
\hline $\begin{array}{l}\text { Observation } \\
\text { period (months) }\end{array}$ & $43.3(7.9-109.5)$ & $61.3(5.4-107.7)$ & 0.229 \\
\hline Age (years) & $65(46-78)$ & $70(60-91)$ & 0.259 \\
\hline$<65$ & 8 & 2 & \\
\hline$\geq 65$ & 14 & 11 & \\
\hline \multicolumn{4}{|l|}{ Gender } \\
\hline Male & 19 & 10 & 0.648 \\
\hline Female & 3 & 3 & \\
\hline \multicolumn{4}{|l|}{ Smoking } \\
\hline Yes & 15 & 10 & 0.709 \\
\hline No & 7 & 3 & \\
\hline \multicolumn{4}{|l|}{ Histology } \\
\hline Adenocarcinoma & 14 & 4 & 0.078 \\
\hline $\begin{array}{l}\text { Squamous cell } \\
\text { carcinoma }\end{array}$ & 7 & 9 & \\
\hline Others & 1 & 0 & \\
\hline \multicolumn{4}{|l|}{ Surgical procedure } \\
\hline Lobectomy & 19 & 11 & 1 \\
\hline Bilobectomy & 2 & 1 & \\
\hline Pneumonectomy & 1 & 1 & \\
\hline \multicolumn{4}{|c|}{ Lymph node dissection } \\
\hline ND2a-1 & 8 & 9 & 0.086 \\
\hline ND2a-2 & 14 & 4 & \\
\hline \multicolumn{4}{|l|}{ Pathological T } \\
\hline $1 \mathrm{a}$ & 1 & 0 & 0.701 \\
\hline $1 \mathrm{~b}$ & 4 & 3 & \\
\hline $1 \mathrm{c}$ & 5 & 5 & \\
\hline $2 \mathrm{a}$ & 11 & 4 & \\
\hline $2 b$ & 1 & 1 & \\
\hline \multicolumn{4}{|l|}{$\mathrm{pl}$} \\
\hline 0 & 16 & 13 & 0.065 \\
\hline $1-3$ & 6 & 0 & \\
\hline \multicolumn{4}{|l|}{ ly } \\
\hline 0 & 4 & 6 & 0.123 \\
\hline $1-2$ & 18 & 7 & \\
\hline \multicolumn{4}{|l|}{$\mathrm{v}$} \\
\hline 0 & 15 & 7 & 0.48 \\
\hline $1-2$ & 7 & 6 & \\
\hline \multicolumn{4}{|c|}{ Adjuvant chemotherapy } \\
\hline Platinum doublet & 12 & 3 & 0.272 \\
\hline Others & 2 & 2 & \\
\hline None & 8 & 8 & \\
\hline \multicolumn{4}{|l|}{ Recurrence } \\
\hline Yes & 14 & 3 & 0.035 \\
\hline No & 8 & 10 & \\
\hline
\end{tabular}

LN metastasis, and compared the background characteristics, clinical courses, and administration of adjuvant chemotherapy.

Patients who received preoperative chemotherapy or radiation therapy were excluded from the study. After resection, LN retrieval was performed by a surgeon, and pathological diagnoses were performed by at least two pathologists. After definitive staging, the administration and regimen of adjuvant chemotherapy was determined by a cancer board consisting of a thoracic surgeon, a radiologist, and an oncologist. The regimen was selected based on platinum-doublet (cisplatin and vinorelbine) and modified according to the patient's condition. All patients underwent follow-up examinations every 2-4 months, consisting of chest X-rays and measurement of tumor markers, and computed tomography was performed at 6 and 12 months and every year thereafter.

Overall survival (OS) and disease-free survival (DFS) were analyzed using the Kaplan-Meier method, and differences were assessed using the log-rank test. Differences in clinicopathological factors between patients in the hilar and intralobar groups were assessed using the Mann-Whitney $U$-test and the $\chi^{2}$ test. Statistical significance was set at $p<0.05$. All statistical analyses were performed using EZR (Saitama Medical Center, Jichi Medical University, Saitama, Japan), which is a graphical user interface of $\mathrm{R}$, and more precisely, a modified version of the $\mathrm{R}$ commander (The R Foundation for Statistical Computing, Vienna, Austria) (11).

\section{Results}

Table I shows the patient characteristics according to location of the LN metastasis. Twenty-two patients had hilar LN metastasis and 13 patients had intralobar LN metastasis. The median follow-up period was 57.8 months. Patients in the hilar group had a significantly higher incidence of postoperative recurrence than those in the intralobar group $(p=0.035)$. There was no significant difference in surgical procedure, lymph node dissection, pathological type, and adjuvant chemotherapy.

Figure 1 shows the 5-year OS and disease-free survival (DFS) rates in 35 patients according to the location of lymph node metastasis. There was a significant difference in the OS $(p=0.042)$ and DFS rates $(p=0.021)$ between patients in the intralobar and hilar groups.

Figure 2 shows the 5-year OS and DFS rates according to adjuvant chemotherapy. Patients who did not receive adjuvant chemotherapy had a poorer OS rate than those who received adjuvant chemotherapy $(p=0.009)$, but there was no significant difference in DFS rate according to adjuvant chemotherapy $(p=0.053)$.

Figure 3 shows 5-year OS and DFS rates in patients in intralobar group according to the adjuvant chemotherapy. There was no significant difference in OS and DFS rates according to the use of adjuvant chemotherapy.

Figure 4 shows 5-year OS and DFS rates in patients in the hilar group according to the adjuvant chemotherapy. Patients without adjuvant chemotherapy had poorer OS $(p<0.001)$ and DFS rates $(p<0.001)$ than patients with adjuvant chemotherapy.

\section{Discussion}

In this study, we showed that the importance of adjuvant chemotherapy for patients with pN1 NSCLC differs according to location of LN metastasis. OS and DFS rates 
A

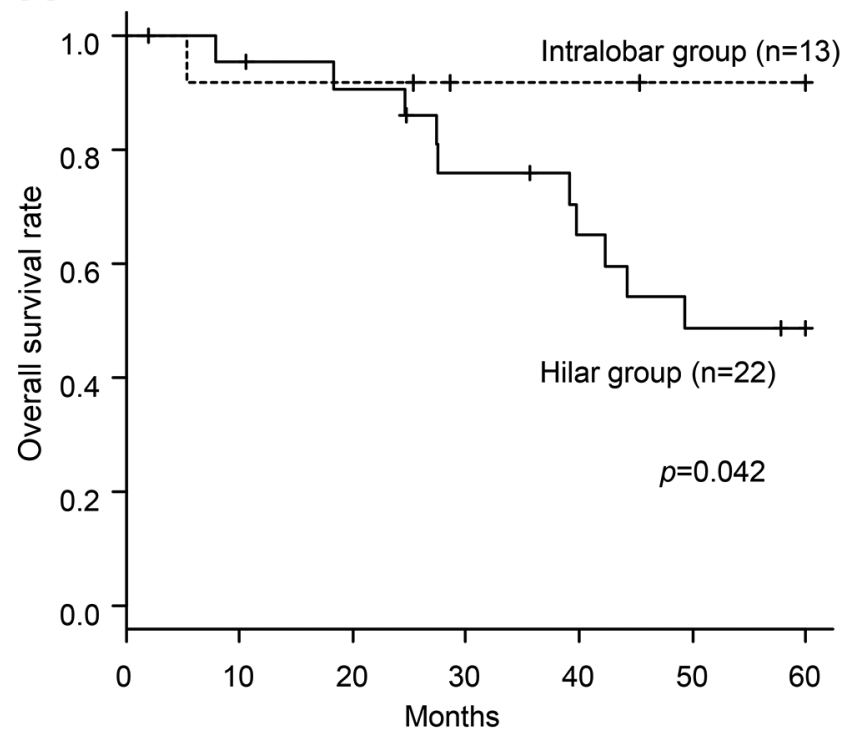

B

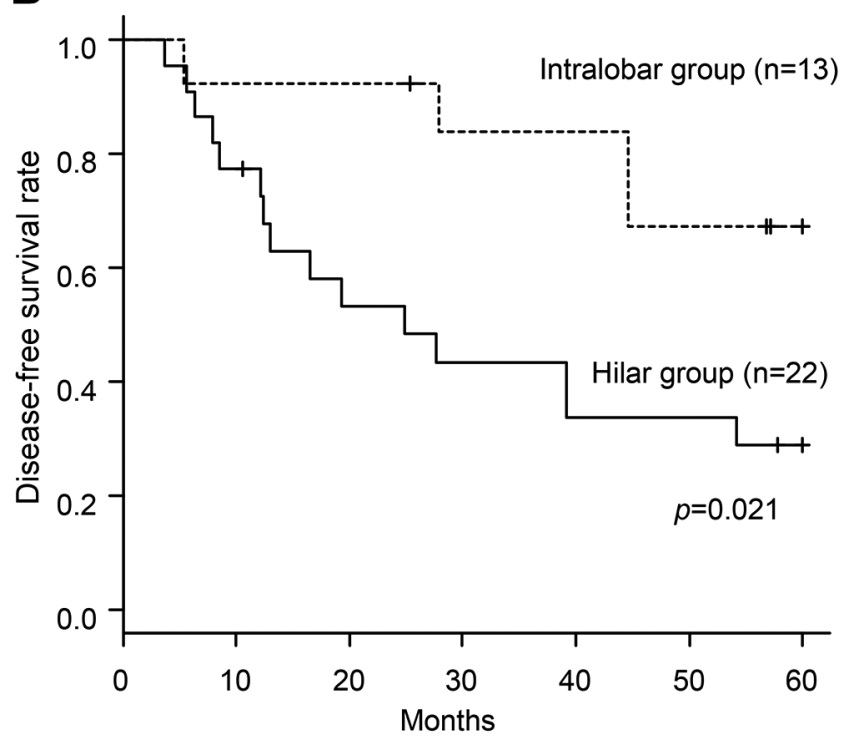

Figure 1. The 5-year overall survival rate (A) and disease-free survival rate (B) in 35 patients according to location of lymph node metastasis.

A

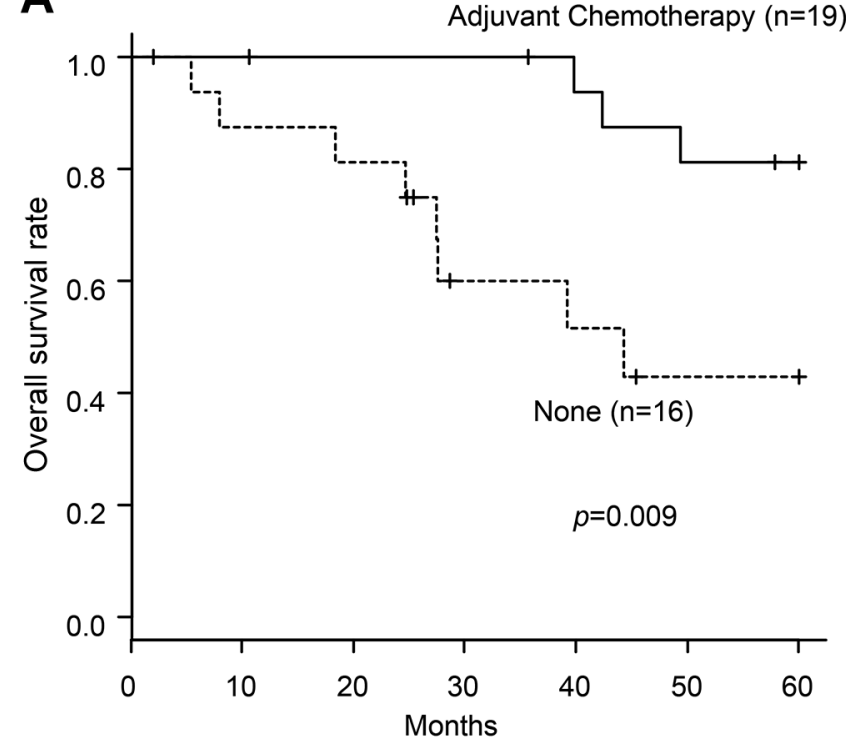

B

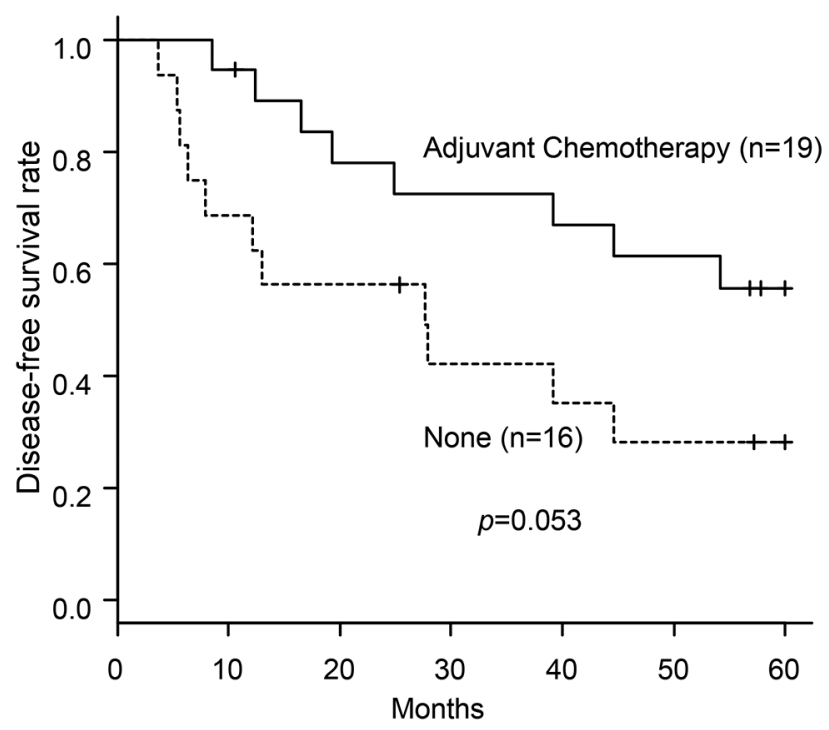

Figure 2. The 5-year overall survival rate (A) and disease-free survival rate (B) according to adjuvant chemotherapy.

were significantly different in the hilar group but not in the intralobar group.

In patients with lung cancer after curative resection, the purpose of adjuvant chemotherapy is to prevent recurrence due to microscopic residual tumors. In this study, we showed the survival benefit of adjuvant chemotherapy according to the station of the $\mathrm{N} 1$ lymph node in patients with pathological T1-2N1 NSCLC. Based on the results of several phase III trials reported in the 2000s, adjuvant chemotherapy for patients with stage II or III NSCLC is mainly cisplatin-based chemotherapy. Several trials have shown a prognostic benefit in 5-year survival rates in postoperative cisplatin-based chemotherapy compared to surgery alone (1-3). The LACE trial, a meta-analysis of 

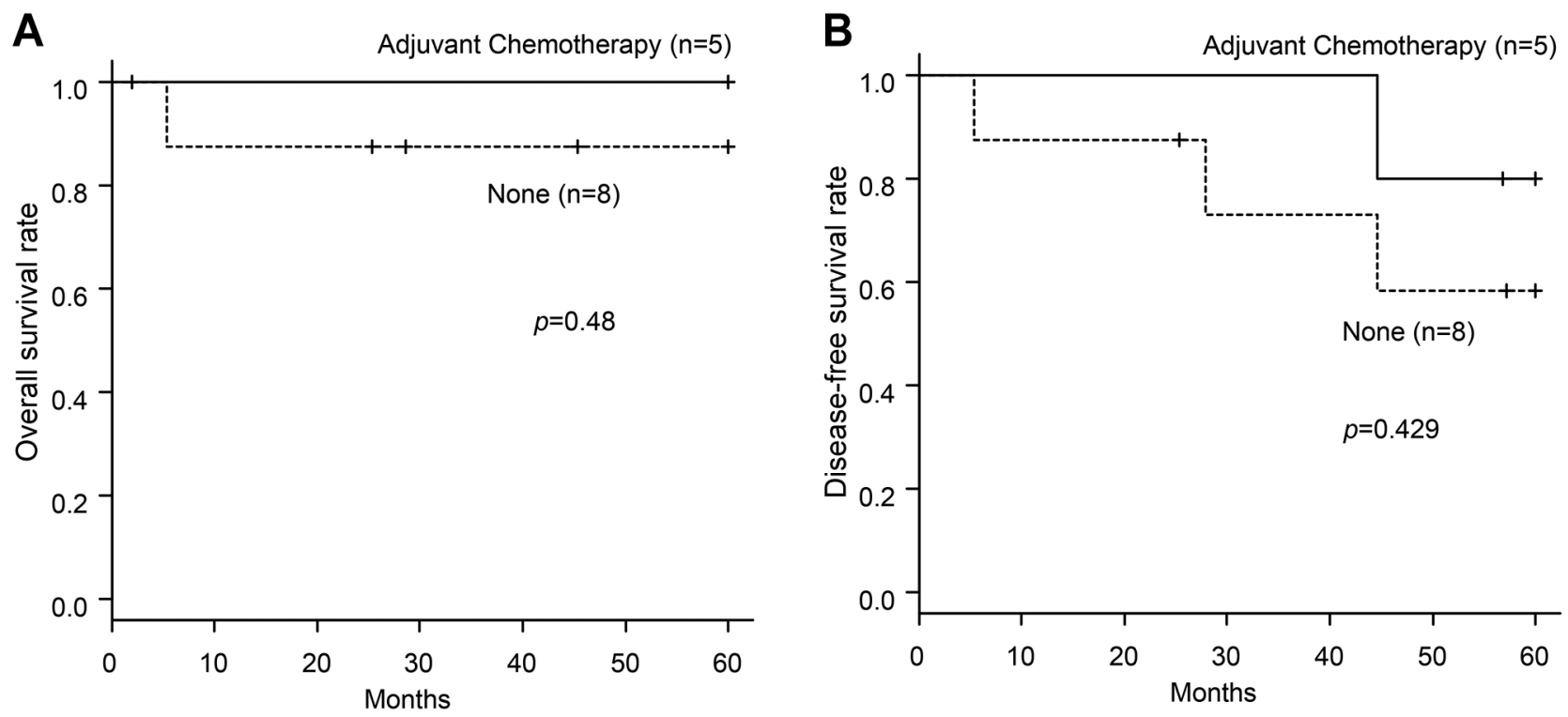

Figure 3. The 5-year overall survival rate $(A)$ and disease-free survival rate $(B)$ in patients in the intralobar group according to adjuvant chemotherapy.
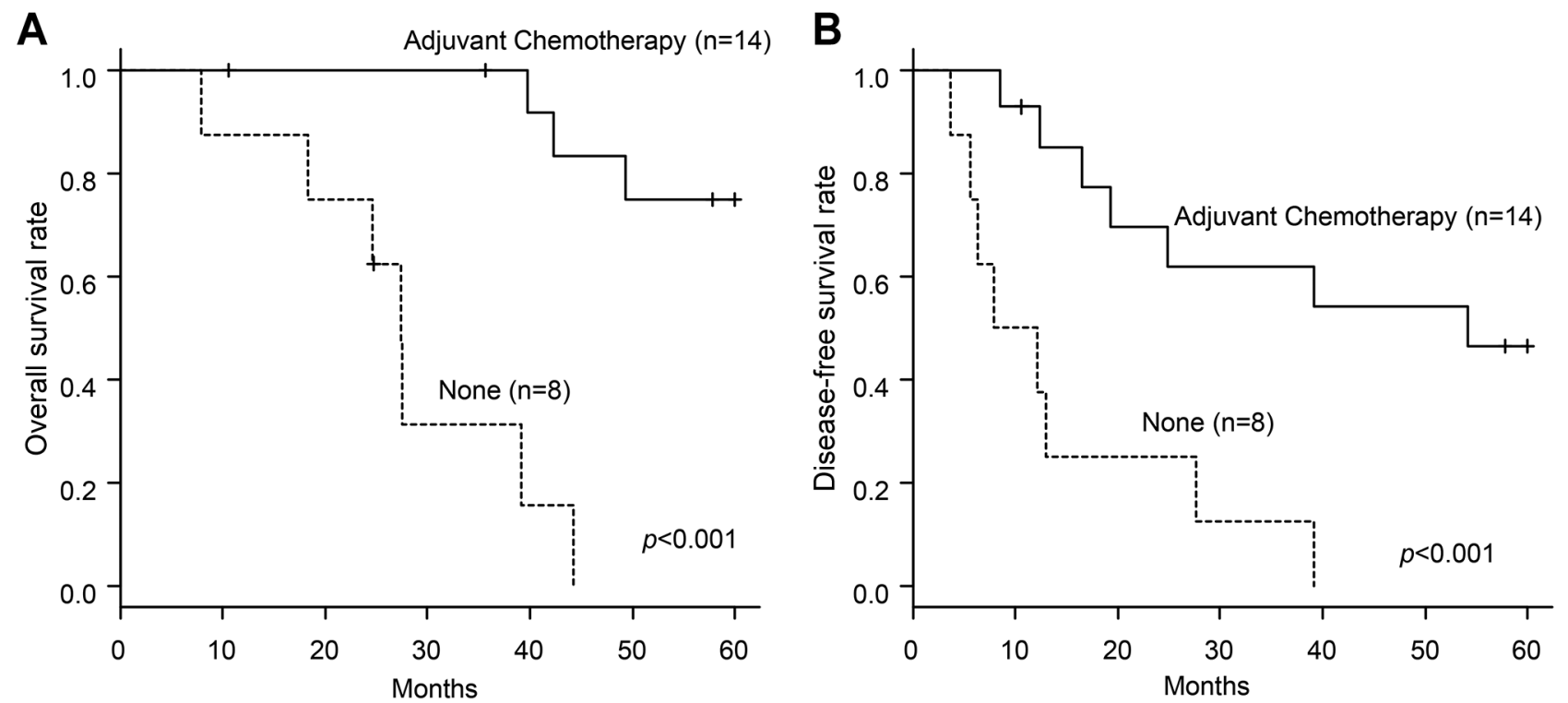

Figure 4. The 5-year overall survival rate (A) and disease-free survival rate (B) in patients in the hilar group according to adjuvant chemotherapy.

IALT, JBR10, ANITA, ALPI, and BLT, showed that postoperative cisplatin-based chemotherapy had a significant prognostic benefit of $5.4 \%$ in 5 -year survival rates compared to surgery alone (4). In our study, we also found a significant difference in the 5-year survival rate between patients with and without postoperative adjuvant chemotherapy in patients with pN1 stage IIB NSCLC.
However, ANITA showed better benefit of adjuvant chemotherapy in 5-year overall survival in patients with $\mathrm{N} 2$ status $(40 \%$ vs. $19 \%, \mathrm{HR}=0.60 ; 95 \% \mathrm{CI}=0.44-0.82)$ than patients with $\mathrm{N} 1$ status ( $52 \%$ vs. $36 \%$; HR, 0.67 ; $95 \%$ $\mathrm{CI}=0.47-0.94)$ (1), and IALT did not show survival benefit in pathological $\mathrm{T} 1-2 \mathrm{~N} 1$ disease $(\mathrm{HR}=0.94 ; 95 \% \mathrm{CI}=0.80$ 1.11) (2). The reason for the difference in survival benefit 
of adjuvant chemotherapy according to $\mathrm{N}$ status might be that the intralobar group in patients with $\mathrm{pN} 1$ did not benefit from adjuvant chemotherapy.

Pathologic N1 LNs are classified into five stations corresponding to their anatomical locations: the hilar LNs, interlobar LNs, lobar LNs, segmental LNs, and subsegmental LNs, termed stations 10, 11, 12, 13, and 14, respectively (6). It is commonly reported that prognosis in $\mathrm{pN} 1$ patients is different in the location of metastatic LNs (7-10, 12). Furthermore, Mordant et al. reported that the presence of $\mathrm{pN} 1$ only at stations 12,13 , and 14 did not affect overall survival (13). In our study, we defined the border between stations 12 and 13 because station 12 is close to station 11 , and sometimes it is quite difficult to distinguish intraoperative findings. This indicates that when metastasis was found at station 12, the metastatic tumor could exist at station 11 and reach station 12 in the other lobe. Our study determined a different definition of borderline in $\mathrm{N} 1$ station compared to previous reports, but showed similar results: the intralobar group had a significantly better prognosis than the hilar group. This supports the finding that the location of lymph node metastasis in pN1 has an impact on prognosis.

To the best of our knowledge, this is the first report to show that prognosis according to the adjuvant chemotherapy differs according to location of lymph node metastasis. In our study, we found a significant prognostic difference in the hilar group with and without adjuvant chemotherapy, but no significant difference was observed in the intralobar group. Thus, there is a possibility that some of the $\mathrm{pN} 1$ patients who received cisplatin-based adjuvant chemotherapy may have received excessive postoperative therapy, especially in the intralobar group. The intralobar group had a good prognosis regardless of adjuvant chemotherapy; however, as long as there is lymph node metastasis, it is certain that tumor cells are in the lymphatic stream. The criteria for platinum doublet as adjuvant chemotherapy should be considered carefully, and even if postoperative management is performed as equivalent to N0, careful follow-up is necessary.

This study has several limitations. First, this was a retrospective study and included a small number of patients. The prognosis of patients with resected NSCLC can be affected by various factors such as nutritional status (14), but none of the factors could be analyzed in all patients, and some patients dropped out and were not followed-up. Accumulation of data on more patients and further investigations are ongoing. Second, LN retrieval after surgery was performed by the surgeons, but not by the same person every time. Therefore, the quality of LN retrieval could be different at each time point. Third, the regimen of adjuvant chemotherapy was not the same in this study group, and treatment after recurrence may be different between observation periods in this study and now.
In conclusion, the prognosis of patients with pN1 stage IIB NSCLC differs significantly according to the location of lymph node metastasis. There was a significant difference in prognosis according to adjuvant chemotherapy in the hilar group. In patients with pN1 NSCLC, postoperative management, including the indication for adjuvant chemotherapy, should be considered carefully according to the location of LN metastasis.

\section{Conflicts of Interest}

The Authors have no conflicts of interest regarding this study.

\section{Authors' Contributions}

Conception and design: Ryuichi Ito, Takuma Tsukioka. Administrative support: Ryuichi Ito, Takuma Tsukioka. Provision of study materials or patients: Ryuichi Ito, Takuma Tsukioka, Nobuhiro Izumi, Hiroaki Komatsu, Hidetoshi Inoue, Takuya Kimura, Kazuya Kishimoto, Noritoshi Nishiyama. Collection and assembly of data: Ryuichi Ito. Data analysis and interpretation: Ryuichi Ito, Takuma Tsukioka, Nobuhiro Izumi, Hiroaki Komatsu, Hidetoshi Inoue, Noritoshi Nishiyama. Manuscript writing: Ryuichi Ito.

Final approval of manuscript: All Authors.

\section{Acknowledgements}

The Authors thank all the patients and medical staff who contributed to this study.

\section{References}

1 Douillard JY, Rosell R, De Lena M, Carpagnano F, Ramlau R, Gonzáles-Larriba JL, Grodzki T, Pereira JR, Le Groumellec A, Lorusso V, Clary C, Torres AJ, Dahabreh J, Souquet PJ, Astudillo J, Fournel P, Artal-Cortes A, Jassem J, Koubkova L, His P, Riggi M and Hurteloup P: Adjuvant vinorelbine plus cisplatin versus observation in patients with completely resected stage IB-IIIA non-small-cell lung cancer (Adjuvant Navelbine International Trialist Association [ANITA]): a randomised controlled trial. Lancet Oncol 7(9): 719-727, 2006. PMID: 16945766. DOI: 10.1016/S14702045(06)70804-X

2 Arriagada R, Bergman B, Dunant A, Le Chevalier T, Pignon JP, Vansteenkiste $\mathrm{J}$ and International Adjuvant Lung Cancer Trial Collaborative Group: Cisplatin-based adjuvant chemotherapy in patients with completely resected non-small-cell lung cancer. N Engl J Med 350(4): 351-360, 2004. PMID: 14736927. DOI: 10.1056/NEJMoa031644

3 Winton T, Livingston R, Johnson D, Rigas J, Johnston M, Butts C, Cormier Y, Goss G, Inculet R, Vallieres E, Fry W, Bethune D, Ayoub J, Ding K, Seymour L, Graham B, Tsao MS, Gandara D, Kesler K, Demmy T, Shepherd F, National Cancer Institute of Canada Clinical Trials Group and National Cancer Institute of the United States Intergroup JBR.10 Trial Investigators: Vinorelbine plus cisplatin $v s$. observation in resected non-smallcell lung cancer. N Engl J Med 352(25): 2589-2597, 2005. PMID: 15972865. DOI: 10.1056/NEJMoa043623 
4 Pignon JP, Tribodet H, Scagliotti GV, Douillard JY, Shepherd FA, Stephens RJ, Dunant A, Torri V, Rosell R, Seymour L, Spiro SG, Rolland E, Fossati R, Aubert D, Ding K, Waller D, Le Chevalier T and LACE Collaborative Group: Lung adjuvant cisplatin evaluation: a pooled analysis by the LACE Collaborative Group. J Clin Oncol 26(21): 3552-3559, 2008. PMID: 18506026. DOI: 10.1200/JCO.2007.13.9030

5 Qi L, Luo Q, Zhang Y, Jia F, Zhao Y and Wang F: Advances in toxicological research of the anticancer drug cisplatin. Chem Res Toxicol 32(8): 1469-1486, 2019. PMID: 31353895. DOI: 10.1021/acs.chemrestox.9b00204

6 Mountain CF and Dresler CM: Regional lymph node classification for lung cancer staging. Chest 111(6): 1718-1723, 1997. PMID: 9187199. DOI: 10.1378/chest.111.6.1718

7 Demir A, Turna A, Kocaturk C, Gunluoglu MZ, Aydogmus U, Urer N, Bedirhan MA, Gurses A and Dincer SI: Prognostic significance of surgical-pathologic N1 lymph node involvement in non-small cell lung cancer. Ann Thorac Surg 87(4): 10141022, 2009. PMID: 19324121. DOI: 10.1016/j.athoracsur. 2008.12.053

8 Maeshima AM, Tsuta K, Asamura $\mathrm{H}$ and Tsuda H: Prognostic implication of metastasis limited to segmental (level 13) and/or subsegmental (level 14) lymph nodes in patients with surgically resected nonsmall cell lung carcinoma and pathologic N1 lymph node status. Cancer 118(18): 4512-4518, 2012. PMID: 22282325. DOI: $10.1002 /$ cncr.27424

9 Li ZM, Ding ZP, Luo QQ, Wu CX, Liao ML, Zhen Y, Chen ZW and $\mathrm{Lu}$ S: Prognostic significance of the extent of lymph node involvement in stage II-N1 non-small cell lung cancer. Chest 144(4): 1253-1260, 2013. PMID: 23744276. DOI: 10.1378/ chest.13-0073
10 Rena O, Boldorini R, Papalia E, Turello D, Massera F, Davoli F, Roncon A, Baietto $\mathrm{G}$ and Casadio C: Metastasis to subsegmental and segmental lymph nodes in patients resected for non-small cell lung cancer: prognostic impact. Ann Thorac Surg 97(3): 987-992, 2014. PMID: 24480258. DOI: 10.1016/ j.athoracsur.2013.11.051

11 Kanda Y: Investigation of the freely available easy-to-use software 'EZR' for medical statistics. Bone Marrow Transplant 48(3): 452-458, 2013. PMID: 23208313. DOI: 10.1038/ bmt.2012.244

12 Riquet M, Manac'h D, Le Pimpec-Barthes F, Dujon A and Chehab A: Prognostic significance of surgical-pathologic N1 disease in non-small cell carcinoma of the lung. Ann Thorac Surg 67(6): 1572-1576, 1999. PMID: 10391257.

13 Mordant P, Pricopi C, Legras A, Arame A, Foucault C, Dujon A, Le Pimpec-Barthes F and Riquet M: Prognostic factors after surgical resection of N1 non-small cell lung cancer. Eur J Surg Oncol 41(5): 696-701, 2015. PMID: 25454825. DOI: 10.1016/ j.ejso.2014.10.003

14 Matsubara T, Hirai F, Yamaguchi $M$ and Hamatake $M$ : Immunonutritional indices in non-small-cell lung cancer patients receiving adjuvant platinum-based chemotherapy. Anticancer Res 41(10): 5157-5163, 2021. PMID: 34593467. DOI: 10.21873/ anticanres. 15333
Received October 8, 2021

Revised November 5, 2021 Accepted November 18, 2021 